\title{
Strong correlation between Helicobacter pylori seropositivity and Chlamydia pneumoniae IgG concentrations
}

\author{
John Danesh, Yuk-Ki Wong, Michael Ward, Peter Hawtin, Mike Murphy, John Muir
}

\section{Clinical Trial Service \\ Unit and \\ Epidemiological \\ Studies Unit, \\ University of Oxford \\ J Danesh}

ICRF General Practice

Research Group,

Institute of Health

Sciences, University of

Oxford

M Murphy

J Muir

Cardiology and

Molecular

Microbiology

Departments,

Southampton

University Medical

School

Y-K Wong

$M$ Ward

Public Health

Laboratories,

Southampton

P Hawtin

Correspondence to: Dr J Danesh, CTSU and Epidemiological Studies Unit, Radcliffe Infirmary, Oxford OX2 6HE.

Accepted for publication 15 June 1998
Overall, epidemiological studies indicate a weakly positive association between coronary heart disease (CHD) and chronic Helicobacter pylori infection. ${ }^{1}$ If $H$ pylori infection increases the incidence of $\mathrm{CHD}$, then it may do so by affecting some other vascular risk factor(s). If there is a non-causal association between the infection and CHD, then this must be because of some confounding factors. In either case, it is of interest to know whether $H$ pylori is correlated with standard vascular risk factors, blood markers of inflammation or of other persistent infections that have been investigated in relation to $\mathrm{CHD}$, such as Chlamydia pneumoniae or cytomegalovirus. We report on the possible correlates of $H$ pylori in a British population-based study.

\section{Methods}

A total of 8000 volunteers aged 35-64 at entry to a trial of health checks by nurses in Bedfordshire general practices completed questionnaires and gave venous blood samples that were

Table 1 Vascular risk factors and other characteristics by Helicobacter pylori seropositivity in 641 people

\begin{tabular}{|c|c|c|c|c|}
\hline Characteristic & $\begin{array}{l}\text { Seropositive } \\
(n=294)\end{array}$ & $\begin{array}{l}\text { Seronegative } \\
(n=347)\end{array}$ & $t \dagger$ & $t \neq$ \\
\hline \multicolumn{5}{|l|}{ Standard vascular risk factors } \\
\hline Age (y) & $60.1(5.8)$ & $58.0(6.2)$ & 4.5 & $2.8^{\star}$ \\
\hline Male & $199(68 \%)$ & $233(67 \%)$ & 0.2 & 0.2 \\
\hline Current smokers & $102(35 \%)$ & $85(25 \%)$ & 3.2 & $2.6^{\star}$ \\
\hline Body mass index $\left(\mathrm{kg} / \mathrm{m}^{2}\right) \quad(\mathrm{n}=640)$ & $26.1(3.8)$ & $26.2(3.8)$ & 0.2 & 0.2 \\
\hline Total cholesterol $(\mathrm{mmol} / \mathrm{l})$ & $6.29(1.24)$ & $6.36(1.21)$ & 0.7 & 1.5 \\
\hline Low density lipoprotein cholesterol $(\mathrm{mmol} / \mathrm{l})$ & $3.75(1.44)$ & $3.63(1.50)$ & 1.0 & 1.0 \\
\hline High density lipoprotein cholesterol ( $\mathrm{mmol} / \mathrm{l})$ & $1.27(0.40)$ & $1.32(0.41)$ & 1.5 & 0.6 \\
\hline Triglycerides $(\mathrm{mmol} / \mathrm{l})$ & $2.16(1.35)$ & $2.13(1.29)$ & 0.2 & 0.7 \\
\hline Systolic blood pressure (mm Hg) & $138(22)$ & $134(22)$ & 2.0 & 0.5 \\
\hline Diastolic blood pressure ( $\mathrm{mm} \mathrm{Hg}$ ) & $79(13)$ & $79(12)$ & 0.1 & 0.2 \\
\hline Physically inactive & $215(73 \%)$ & $260(75 \%)$ & 1.0 & 1.4 \\
\hline \multicolumn{5}{|l|}{ Markers of persistent infection } \\
\hline Chlamydia pneumoniae concentrations $\left(\mathrm{FC} \times 10^{6}\right)(\mathrm{n}=640)$ & $114.6(33.9)$ & $93.4(41.2)$ & 7.0 & $5.9^{\star \star \star}$ \\
\hline Cytomegalovirus values $\left(\mathrm{FC} \times 10^{6}\right)(\mathrm{n}=640)$ & $90.9(55.30$ & $81.8(59.8)$ & 2.0 & 0.9 \\
\hline \multicolumn{5}{|l|}{ Markers of inflammation } \\
\hline $\log _{\mathrm{e}} \mathrm{C}$-reactive protein $(\mathrm{mg} / \mathrm{l})$ & $0.71(1.22)$ & $0.49(1.27)$ & 2.2 & 0.4 \\
\hline $\log _{\text {s }}$ serum amyloid $\mathrm{A}(\mathrm{mg} / \mathrm{l})$ & $0.95(0.99)$ & $0.82(0.95)$ & 1.6 & 0.9 \\
\hline \multicolumn{5}{|l|}{ Markers of socioeconomic status } \\
\hline Without own $\operatorname{car}(n=636)$ & $72(25 \%)$ & $42(12 \%)$ & 4.2 & $3.6^{\star \star}$ \\
\hline In rented housing $(n=632)$ & $66(23 \%)$ & $31(9 \%)$ & 2.7 & 2.1 \\
\hline Completed education by 16 years $(n=630)$ & $264(92 \%)$ & $279(81 \%)$ & 3.8 & $3.1^{\star}$ \\
\hline Employed $(n=637)$ & $175(60 \%)$ & $237(69 \%)$ & 1.6 & 0.3 \\
\hline Manual workers & $140(48 \%)$ & $121(35 \%)$ & 1.9 & 1.0 \\
\hline Married $(n=630)$ & $240(83 \%)$ & $292(86 \%)$ & 0.5 & 0.1 \\
\hline
\end{tabular}

$\mathrm{FC}=$ Fluorescence counts. ${ }^{\star} \mathrm{p}<0.01,{ }^{\star \star} \mathrm{p}<0.001,{ }^{\star \star \star} \mathrm{p}<0.00001 . \dagger t$ Tests derived from regression of $H$ pylori seropositivity on each characteristic separately. $\ddagger t$ Tests derived from regression of $H$ pylori seropositivity adjusting for sex, age, and body mass index (as continuous variables), smoking (current smoker, former smoker, current tobacco consumption, and pack years as continuous variables), and social class (car ownership, housing tenure, age at stopping full time education, employment status, job classification, and marital status). Adjustments for social class were omitted in the regressions involving markers of socioeconomic status. Data shown as mean (SD) and number (percentage). stored at $-80^{\circ} \mathrm{C} .^{2}$ In the samples of 641 people without a history of CHD who were the controls in another study, measurements were made of blood lipids with standard assays, of C reactive protein and serum amyloid A protein with sensitive immunoassays (IM $x$, Abbott to $H$ pylori with a commercial ELISA kit (Orion, Pyloriset, Espoo, Finland), and of IgG antibodies to $C$ pneumoniae (whole organism antigen) and to cytomegalovirus (whole organism antigen) with time resolved fluorimetry ELFIA, Wallac, Turku, Finland). Our $C$ pneumoniae assay showed good agreement with standard microimmunofluoresence in the (Y-K Wong et al, unpublished data) but $C$ pneumoniae serology is generally prone to poor reproducibility. ${ }^{1}$

\section{Results} positivity with age and poverty were seen. ${ }^{1}$ Laboratories, Illinois, USA), of IgG antibodies

The well known associations of $H$ pylori sero- 
(Table 1). There was a strong correlation between $H$ pylori seropositivity and $C$ pneumoniae serum IgG concentrations $(\mathrm{p}<0.00001)$, and this was not much changed after adjustment for age, sex, smoking, and markers of social class. The adjusted odds ratio of $H$ pylori seropositivity for the top third of $C$ pneumoniae concentrations was 2.9 (99\% confidence limits 1.4 to $6.2 ; \mathrm{p}<0.00001)$. As reported in a recent meta-analysis with information on 10000 people, there were no strong correlations between $H$ pylori seropositivity and body mass index, blood pressure, or blood concentrations of lipids or $\mathrm{C}$ reactive protein. ${ }^{3}$ There were also no strong correlations with other factors not reported on previously, such as with exercise or with concentrations of cytomegalovirus serum IgG antibodies or of serum amyloid A protein (table 1).

\section{Discussion}

A previous study in 300 healthy British men used microimmunofluorescence to measure $C$ pneumoniae antibody concentrations, and it reported no strong correlation between $H$ pylori seropositivity and $C$ pneumoniae seropositivity. ${ }^{4}$ As larger reports involving measurement of both agents are not available, the strong association between $H$ pylori seropositivity and $C$ pneumoniae serum IgG concentrations observed in this study of 640 people should be regarded as provisional. $H$ pylori is spread from mouth to mouth and/or by the faecal-oral route, whereas $C$ pneumoniae is spread in respiratory secretions. ${ }^{1}$ Apart from age and, perhaps, poverty (which were standardised for in the study), the agents share no known risk factors, so such factors cannot explain the strong association observed in this population. Each of these Gram negative bacteria has been investigated in relation to $\mathrm{CHD},{ }^{1}$ but as the present study included only people without a history of CHD, it is very unlikely that the presence of unrecognised vascular disease could have artefactually produced these results. The possibility of a spurious association caused by cross reactive antibodies-for example, an immune response to heat shock protein- $60^{5}$ - should be tested in future studies. If larger reports demonstrate an association between the presence of $H$ pylori and $C$ pneumoniae, it would suggest that studies should investigate the possible relevance of coinfection by these and other persistent agents, particularly in relation to CHD.

Alice Fuller helped with data management, and Jenny Jay and Janet Robertson retrieved blood samples. This study was supported by a grant from the Oxfordshire Health Services Research Committee.

Funding: JD is supported by a Merton College junior research fellowship.

Conflicts of interest: none.

1 Danesh J, Collins R, Peto R. Chronic infections and coronary heart disease: is there a link? Lancet 1997;350:430-6.

2 Imperial Cancer Research Fund OXCHECK Study Group. Prevalence of risk factors for heart disease in OXCHECK trial: implication for screening in primary care. BMF 1991; 302:1057-60

3 Danesh J, Peto R. Risk factors for coronary heart disease and infection with Helicobacter pylori: meta-analysis of 18 studies. BMF 1998;316:1130-2.

4 Patel P, Mendall MA, Carrington D, et al. Association of Helicobacter pylori and Chlamydia pneumoniae infections with coronary heart disease and cardiovascular risk factors. with coronary heart dise

$5 \mathrm{Xu}$ O, Willeit J, Marosi M, et al. Association of serum antibodies to heat-shock protein 65 with carotid atherosclerosis. Lancet 1993;341:255-9. 